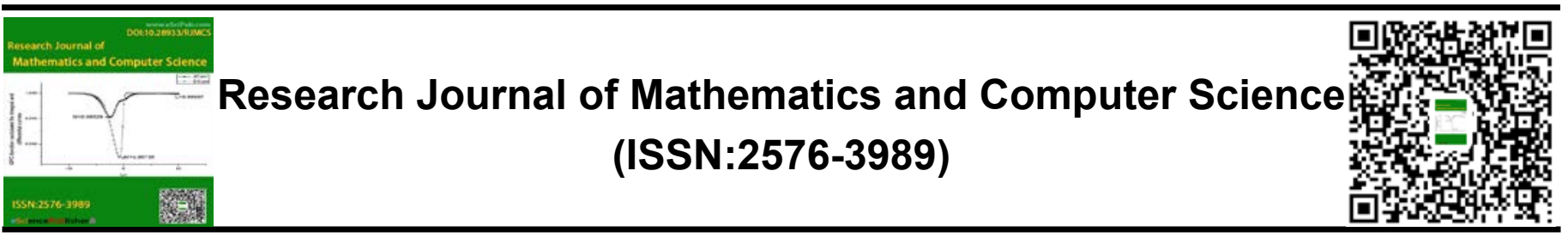

\title{
Comparative Study of a Class of One-Step Methods for the Numerical Solution of Some Initial Value Problems in Ordinary Differential Equations
}

\author{
${ }^{1}$ S.E. Fadugba and ${ }^{2}$ T. E. Olaosebikan \\ 1,2 Department of Mathematics, Ekiti State University, Ado Ekiti, Nigeria
}

\begin{abstract}
We emphasized explicitly on the derivation and implementation of a new one-step numerical method for the solution of initial value problems in ordinary differential equations. In this paper, we aimed at comparing the newly developed method with other existing methods such as Euler's method, Trapezoidal rule and Simpson's rule. Using these methods to solve some initial value problems of first order ordinary differential equations, we discovered that the results compared favorably, which led to the conclusion that the newly derived one-step numerical method is approximately correct and can be used for any related first order ordinary differential equations.
\end{abstract}

Keywords: Numerical solution, One-step method, Ordinary differential equation.
*Correspondence to Author:

S.E. Fadugba

Department of Mathematics, Ekiti State University, Ado Ekiti, Nigeria

How to cite this article:

S.E. Fadugba and T. E. Olaosebikan. Comparative Study of a Class of One-Step Methods for the Numerical Solution of Some Initial Value Problems in Ordinary Differential Equations. Research Journal of Mathematics and Computer Science, 2018; 2:9

\section{eSciencePublisher}

eSciPub LLC, Houston, TX USA. Website: http://escipub.com/ 


\section{INTRODUCTION}

Various numerical methods have been developed for the solution of some initial value problems of ordinary differential equations. Some of the Numerical Analysts who have worked extensively on the development of numerical methods are: Fatunla, (1976), Lambert (1991), Ibijola, (1997 and 1998), Kama and Ibijola (2000), Butcher (2003), Zarina et al. (2005), Aboiyar et al. (2015), Fadugba and Falodun (2017), just to mention a few. The efficiency of all these contributed efforts from these Numerical Analysts in numerical analysis had been measured and tested for their stability, accuracy, convergence and consistency properties. The accuracy properties of different methods are usually compared by considering the order of convergence as well as the truncation error coefficients of the various methods. Research has shown that for a method to be suitable for solving any sets of initial value problems in ordinary differential equations, it must have all the mentioned characteristics. In this paper, we compare a new one-step numerical method with existing methods with the above mentioned characteristics in mind to solve some initial value problems in ordinary differential equations of the form:

$y^{\prime}=f(x, y) ; y(a)=\eta,-\infty<y<\infty, a \leq x \leq b$

in the interval $\left(x_{n}, x_{n+1}\right)$ by interpolating function given by

$F(x)=a_{0}+a_{1} e^{-\alpha x}$

where $a_{0}$ and $a_{1}$ are real undetermined coefficients.

The rest of the paper is organized as follows. Section Two consists of some basic properties. Section Three is the development of the new scheme. Section Four consists of the numerical example, discussion of results and concluding remarks.
We consider the following basic properties namely; stability, consistency and convergence.

(a) Stability: A numerical method is said to be stable if the difference between the numerical solution and the exact solution can be made as small as possible, that is if there exists two positive constant $e_{0}$ and $K$ such that the following holds;

$\left\|y_{n}-y\left(x_{n}\right)\right\| \leq K\left\|e_{0}\right\|$

(b) Consistency: A numerical method with an increment function $\phi\left(x_{n}, y_{n}, h\right)$ is said to be consistent with the initial value problem under consideration if

$$
\phi\left(x_{n}, y_{n}, h\right)=f\left(x_{n}, y_{n}\right)
$$

(c) Convergence: A numerical method is said to be convergent if for all initial value problem satisfying the hypothesis of Lipschitz condition given by

$$
\left|f\left(x, y_{2}\right)-f\left(x, y_{1}\right)\right| \leq L\left|y_{2}-y_{1}\right|
$$

where the Lipschitz constant is denoted by $L$.

Remark 1: The necessary and sufficient conditions for convergence are stability and consistency.

\section{DEVELOPMENT OF A NEW ONE STEP NUMERICAL METHOD}

Suppose we have the initial value problem of the form:

$y^{\prime}=f(x, y) ; y\left(x_{0}\right)=y_{0}$

Let us assume that the theoretical solution $y(x)$ to (6) can be locally represented in the interval $\left(x_{n}, x_{n+1}\right), n \geq 0$ by the interpolating polynomial function:

$F(x)=a_{0}+a_{1} e^{-\alpha x}$

where $a_{0}$, and $a_{1}$ are real undetermined coefficients.

We also assume that $y_{n}$ is a numerical estimate to the theoretical solution $y(x)$ and

\section{SOME BASIC PROPERTIES}


S.E. Fadugba and T. E.Olaosebikan, RJMCS, 2018; 2:9

$f_{n}=f\left(x_{n}, y_{n}\right)$. We define mesh points as Re-arranging terms yield:

follows:

$x_{n}=a+n h, n=0,1,2, \ldots$ or $x_{n+1}=a+(n+$

$y_{n+1}=y_{n}+a_{1}\left(e^{-\alpha x_{n+1}}-e^{-\alpha x_{n}}\right)$

1) $h, n=1,2, \ldots$

Therefore, from (7), we obtain the following derivatives

$F^{1}(x)=-\alpha a_{1} e^{-\alpha x}$

$F^{2}(x)=\alpha^{2} a_{1} e^{-\alpha x}$

From (7), we have that

From the mesh points, we have

$x_{n}=a+n h$

or

$x_{n+1}=a+(n+1) h$

From (15), the term $\left(e^{-\alpha x_{n+1}}-e^{-\alpha x_{n}}\right)$ can be written as

$$
e^{-\alpha x_{n+1}}-e^{-\alpha x_{n}}=e^{-\alpha(a+(n+1) h)}-e^{-\alpha(a+n h)}
$$

$a_{0}=F(x)-a_{1} e^{-\alpha x}$

Also from (8), we obtain

by factorization and setting $a=0$, we have:

$$
e^{-\alpha(a+(n+1) h)}-e^{-\alpha(a+n h)}=e^{-\alpha n h}\left(e^{-\alpha h}-1\right)
$$

$a_{1}=-\frac{F^{1}(x)}{\alpha e^{-\alpha x}}$

Putting (12) into (9), yields

$$
F^{2}(x)=-\alpha F^{1}(x)
$$

Similarly, from (12) and (10), we have:

$a_{0}=F(x)-\frac{F^{1}(x)}{\alpha}$

Now, imposing the following constraints on the interpolating function (7) in the following order:

a. The interpolating function (7) must coincide with the theoretical solution at $x=x_{n}$ and $x=x_{n+1}$ such that:

$F\left(x_{n}\right)=a_{0}+a_{1} e^{-\alpha x_{n}}$

$F\left(x_{n+1}\right)=a_{0}+a_{1} e^{-\alpha x_{n+1}}$

b. The derivative of $F^{1}(x), F^{2}(x)$ and $F^{n}(x)$ coincide with $f(x), f^{1}(x)$ and $f^{n-1}(x)$ respectively. That is;

$F^{1}(x)=f_{n}$

$F^{2}(x)=f_{n}^{1}$

From conditions (a) and (b) above, it follows that:

$$
F\left(x_{n+1}\right)-F\left(x_{n}\right) \equiv y_{n+1}-y_{n}
$$

Therefore, we have:

$a_{0}+a_{1} e^{-\alpha x_{n+1}}-\left(a_{0}+a_{1} e^{-\alpha x_{n}}\right)=y_{n+1}-y_{n}$

Putting (12) and (16) in (15), we have the new scheme follow:

$$
y_{n+1}=y_{n}-\frac{f_{n}}{\alpha}\left(e^{-\alpha h}-1\right)
$$

Using power series expansion to fourth term and by factorization, (17) becomes:

$$
y_{n+1}=y_{n}-h\left(-1+\frac{\alpha h}{2 !}-\frac{\alpha^{2} h^{2}}{3 !}\right) f_{n}
$$

Equation (18) is the proposed one-step method.

3.1 Properties of the Scheme

3.1.1 Convergence of the Scheme

We establish the numerical integration algorithm for which (18) can be expressed as one-step method in the form:

$y_{n+1}=x_{n}+h \emptyset\left(x_{n}, y_{n} ; h\right)$

where $\varnothing\left(x_{n}, y_{n} ; h\right)$ is the increment function. We proceed to derive the increment function for our scheme from:

$F(x)=a_{0}+a_{1} e^{-\alpha x}$

If we assume that the point $x=x_{n}$ and $x=$ $x_{n+1}$

Then:

$$
F\left(x_{n}\right)=a_{0}+a_{1} e^{-\propto x_{n}}
$$

and 
$F\left(x_{n+1}\right)=a_{0}+a_{1} e^{-\propto x_{n+1}}$

If we also assume that $f\left(x_{n}\right)$ and $f\left(x_{n+1}\right)$ coincide with $y_{n}$ and $y_{n+1}$ respectively, then let $f^{k}$ denote the kth total derivatives of $f(x, y)$ with respect to $x_{n}$, we have:

$$
\begin{aligned}
& F^{1}\left(x_{n}\right)=-\propto a_{1} e^{-\propto x_{n}}=f_{n} \\
& F^{2}\left(x_{n}\right)=-\propto^{2} a_{1} e^{-\propto x_{n}}=f_{n}^{1}
\end{aligned}
$$

Solving for $a_{1}$ in (22);

$$
a_{1}=-\frac{f_{n}}{\propto e^{-\alpha x_{n}}}
$$

Similarly,

$$
a_{0}=F\left(x_{n}\right)-\frac{f_{n}}{\alpha}
$$

Considering the assumption that $F\left(x_{n}\right)=y_{n}$ and $F\left(x_{n+1}\right)=y_{n+1}$, we have our numerical integrator generated as:

$$
\begin{aligned}
& y_{n+1}-y_{n}=a_{1}\left(e^{-\propto x_{n+1}}-e^{-\propto x_{n}}\right) \\
& y_{n+1}=y_{n}-\frac{f_{n}}{\propto e^{-\alpha x_{n}}}\left(e^{-\propto x_{n+1}}-e^{-\propto x_{n}}\right) \\
& y_{n+1}=y_{n}-\frac{f_{n}}{\propto}\left(e^{-\propto h}-1\right)
\end{aligned}
$$

By expansion and substitution, (26) becomes:

$$
y_{n+1}=y_{n}+h\left[f_{n}-A f_{n}\right]
$$

where

$$
A=\frac{3 \propto h+\propto^{2} h^{2}}{6}
$$

Equation (27) converges since we can write it in the form:

$$
y_{n+1}=y_{n}+h \emptyset\left(x_{n}, y_{n} ; h\right)
$$

where

$$
\emptyset\left(x_{n}, y_{n} ; h\right)=f_{n}-A f_{n}
$$

Equation (28) is therefore called the increment function.
We define any algorithm for solving a differential equation in which the approximate $y_{n+1}$ to the solution at $x_{n+1}$ can be calculated, if only $x_{n}, y_{n}$ and $\mathrm{h}$ are known is called one step method. It is a common practice to write the functional dependence part, $y_{n+1}$ on the quantities $x_{n}, y_{n}$ and $h$ as:

$$
y_{n+1}=y_{n}+h \emptyset\left(x_{n}, y_{n} ; h\right) \text {. }
$$

We observe that:

$$
\emptyset\left(x_{n}, y_{n} ; h\right)=f_{n}-A f_{n}
$$

\section{Theorem 1}

Let the increment function of the scheme defined by (29) be continuous as a function of its three arguments in the region defined by $x \in$ $[a, b], y \in[a, x], 0 \leq h \leq h_{0}$, where $h_{0}>0$, and let there exist a constant $\mathrm{L}$ such that $\left|\varnothing\left(x_{n}, y_{n}^{*} ; h\right)-\emptyset\left(x_{n}, y_{n} ; h\right)\right| \leq L\left|y_{n}^{*}-y_{n}\right|$ for all $\left(x_{n}, y_{n} ; h\right)$ and $\left(x_{n}, y_{n}^{*} ; h\right)$ in the region just defined. Then the relation $\emptyset(x, y ; 0)=f(x, y)$ is a necessary and sufficient condition for the convergence of the method defined by the equation (3.24)

\section{Proof:}

The increment function $\varnothing\left(x_{n}, y_{n}^{*} ; h\right)$ can be written in the form:

$$
\emptyset\left(x_{n}, y_{n}^{*} ; h\right)=f\left(x_{n}, y_{n}\right)-A f\left(x_{n}, y_{n}\right)
$$

Where $\mathrm{A}$ is a constant defined as:

$$
A=\frac{3 \propto h+\alpha^{2} h^{2}}{6} \text {, and } x_{n}=a h \text { at } a \geq 0
$$

Consider equation (30), we can also write

$$
\begin{aligned}
& \emptyset\left(x_{n}, y_{n}^{*} ; h\right)=f\left(x_{n}, y_{n}^{*}\right)+A f\left(x_{n}, y_{n}^{*}\right) \\
& \varnothing\left(x_{n}, y_{n}^{*} ; h\right)-\emptyset\left(x_{n}, y_{n} ; h\right)= \\
& f\left(x_{n}, y_{n}^{*}\right)-f\left(x_{n}, y_{n}\right)+A\left[f\left(x_{n}, y_{n}^{*}\right)-\right. \\
& \left.f\left(x_{n}, y_{n}\right)\right]
\end{aligned}
$$

Let $\bar{y}$ be defined as a point in the interior of the interval whose end points are $y$ and $y^{*}$, applying mean value theorem, we have:

\section{Definition 1}


$\left.y_{n}\right)$

$f\left(x_{n}, y_{n}^{*}\right)-f\left(x_{n}, y_{n}\right)=\frac{\partial f\left(x_{n}, \bar{y}\right)}{\partial y_{n}}\left(y_{n}^{*}-\right.$

We define

$L=\operatorname{Sup}_{\left(x_{n}, y_{n}\right) \in D o m} \frac{\partial f\left(x_{n}, \bar{y}_{n}\right)}{\partial y_{n}}$

therefore

$\emptyset\left(x_{n}, y^{*}{ }_{n} ; h\right)-\emptyset\left(x_{n}, y_{n} ; h\right)=\frac{\partial f\left(x_{n}, \bar{y}\right)}{\partial y_{n}}\left(y_{n}^{*}-\right.$ $\left.y_{n}\right)-A\left[\frac{\partial f\left(x_{n}, \bar{y}\right)}{\partial y_{n}}\left(y_{n}^{*}-y_{n}\right)\right]$

(34)

$$
\begin{aligned}
& \varnothing\left(x_{n}, y^{*}{ }_{n} ; h\right)-\varnothing\left(x_{n}, y_{n} ; h\right)=L\left(y_{n}^{*}-y_{n}\right)+ \\
& A L_{1}\left(y_{n}^{*}-y_{n}\right)
\end{aligned}
$$

Taking the absolute value of both sides, we have:

$$
\begin{aligned}
& \left|\varnothing\left(x_{n}, y_{n}^{*} ; h\right)-\emptyset\left(x_{n}, y_{n} ; h\right)\right| \leq \\
& \left|L+A L_{1}\right|\left|\left(y_{n}^{*}{ }_{n}-y_{n}\right)\right|
\end{aligned}
$$

Let $\mathrm{M}=\left|L+A L_{1}\right|$, then (36) becomes:

$$
\left|\emptyset\left(x_{n}, y_{n}^{*} ; h\right)-\emptyset\left(x_{n}, y_{n} ; h\right)\right| \leq
$$

$$
M\left|y_{n}^{*}-y_{n}\right|
$$

Equation (37) is the necessary condition for convergence of the method.

\subsection{CONSISTENCY OF THE SCHEME}

\section{Definition 2}

A numerical scheme with an increment function $\emptyset\left(x_{n}, y_{n} ; h\right)=f_{n}-A f_{n}$ is said to be consistent with the initial value problem:

$$
y^{1}=f(x, y) ; y\left(x_{0}\right)=y_{0}
$$

Since $\quad y_{n+1}=y_{n}+h \emptyset\left(x_{n}, y_{n} ; h\right)$

$\emptyset\left(x_{n}, y_{n} ; h\right)=f_{n}-A f_{n}$, if $h=0$, then $y_{n+1}=y_{n}$ thus

$$
\emptyset\left(x_{n}, y_{n} ; 0\right)=f(x, y)
$$

Therefore, we say the scheme is consistent.

\subsection{STABILITY ANALYSIS OF THE SCHEME}

\section{Theorem 3}

Let $y_{n}=y\left(x_{n}\right)$ and $p_{n}=p\left(x_{n}\right)$ denote two different numerical solutions of initial value problem of ordinary differential equation (6) with the conditions specified as $y\left(x_{0}\right)=\eta$ and $p\left(x_{0}\right)=\eta^{*}$ respectively, such that $\left|\eta-\eta^{*}\right|<$ $\varepsilon, \varepsilon>0$. If the two numerical estimates are generated by the integration scheme (18), we have:

$$
\begin{aligned}
& y_{n+1}=y_{n}+h \emptyset\left(x_{n}, y_{n} ; h\right) \\
& p_{n+1}=p_{n}+h \emptyset\left(x_{n}, p_{n} ; h\right)
\end{aligned}
$$

The condition that:

$$
\left|y_{n+1}-p_{n+1}\right| \leq k\left|\eta-\eta^{*}\right|
$$

is the necessary and sufficient condition that our new method (18) be stable and convergent.

\section{Proof:}

From (18), we have:

$y_{n+1}=y_{n}+h\left[f_{n}-A f_{n}\right]$

Then let:

$$
\begin{aligned}
& y_{n+1}=y_{n}+h\left[f\left(x_{n}, y_{n}\right)-A f\left(x_{n}, y_{n}\right)\right] \\
& p_{n+1}=p_{n}+h\left[f\left(x_{n}, p_{n}\right)-A f\left(x_{n}, p_{n}\right)\right]
\end{aligned}
$$

Therefore;

$y_{n+1}-p_{n+1}=y_{n}-p_{n}+h\left\{f\left(x_{n}, y_{n}\right)-\right.$ $\left.f\left(x_{n}, p_{n}\right)-A\left[f\left(x_{n}, y_{n}\right)-f\left(x_{n}, p_{n}\right)\right]\right\}$

Applying mean value theorem, we have:

$y_{n+1}-p_{n+1}=y_{n}-p_{n}+h\left\{\frac{\partial f\left(x_{n}, p_{n}\right)}{\partial p_{n}}\left(x_{n}-\right.\right.$ $\left.\left.p_{n}\right)-A\left[\frac{\partial f\left(x_{n}, p_{n}\right)}{\partial p_{n}}\left(x_{n}-p_{n}\right)\right]\right\}$

Define

$$
L=\operatorname{Sup}_{\left(x_{n}, p_{n}\right) \in D o m} \frac{\partial f\left(x_{n}, p_{n}\right)}{\partial p_{n}}
$$

Then we have,

$$
\begin{aligned}
& y_{n+1}-p_{n+1}=y_{n}-p_{n}+h\left\{L\left(x_{n}-p_{n}\right)-\right. \\
& \left.A L_{1}\left(x_{n}-p_{n}\right)\right\}
\end{aligned}
$$

(39) Taking absolute value of both sides, we have: 
$\left|y_{n+1}-p_{n+1}\right| \leq\left|y_{n}-p_{n}\right|+h\left|L-A L_{1}\right| \mid x_{n}-$ $p_{n} \mid$

Let $\quad N=h\left|L-A L_{1}\right| \quad$ and $\quad y\left(x_{0}\right)=\eta, p\left(x_{0}\right)=$ $\eta^{*}, \varepsilon>0$, then

$\left|y_{n+1}-p_{n+1}\right| \leq N\left|x_{n}-p_{n}\right| \quad$ and $\quad \mid y_{n+1}-$ $p_{n+1}|\leq N| \eta-\eta^{*} \mid<\varepsilon, \varepsilon>0$

We conclude that our scheme is stable and hence convergent.

\section{ILLUSTRATIVE EXAMPLES, DISCUSSION OF RESULTS AND CONCLUDING REMARKS}

Here we present some illustrative examples, discussion of results and concluding remarks as follows:

\subsection{ILLUSTRATIVE EXAMPLES}

It is always necessary to demonstrate the applicability, suitability and accuracy of the newly developed one-step numerical method. To do this, the method was rewritten in an algorithm form, translated into computer codes using QBASIC programming language and implemented with sample problems on a digital computer. We consider the following illustrative examples.

\section{Example 1}

$y^{\prime}=x+y, y(0)=1$ with $h=0.1$

The exact solution is obtained as $y(x)=2 e^{x}$ $x-1$

The results and the errors incurred are shown in Tables 1 and 2 respectively.

Table 1: Results for Problem 1 at $h=0.1$

\begin{tabular}{|c|c|c|c|c|}
\hline $\begin{array}{c}\text { Exact } \\
\text { Solution }\end{array}$ & $\begin{array}{c}\text { Euler's } \\
\text { Method }\end{array}$ & $\begin{array}{c}\text { Trapezoidal } \\
\text { Rule }\end{array}$ & $\begin{array}{c}\text { One Step } \\
\text { Numerical } \\
\text { Method }\end{array}$ & $\begin{array}{c}\text { Simpson's } \\
\text { Rule }\end{array}$ \\
\hline 1.11034179 & 1.10000001 & 1.11000000 & 1.10516667 & 1.11000001 \\
\hline 1.24280548 & 1.22000002 & 1.24205001 & 1.23191011 & 1.24266666 \\
\hline 1.39971769 & 1.36200001 & 1.39846525 & 1.38249934 & 1.39914666 \\
\hline 1.58364940 & 1.52820000 & 1.58180410 & 1.55944216 & 1.58255706 \\
\hline 1.79744256 & 1.72102001 & 1.79489353 & 1.76551020 & 1.79572555 \\
\hline 2.04423761 & 1.94312200 & 2.04085735 & 2.00376630 & 2.04177674 \\
\hline 2.32750535 & 2.19743420 & 2.32314737 & 2.27759576 & 2.32416330 \\
\hline 2.65108180 & 2.48177620 & 2.64557784 & 2.59073949 & 2.64670044 \\
\hline 3.01920629 & 2.81589538 & 3.01236352 & 2.94733214 & 3.01360399 \\
\hline 3.43656373 & 3.18748492 & 3.42816169 & 3.35194325 & 3.42953241 \\
\hline
\end{tabular}




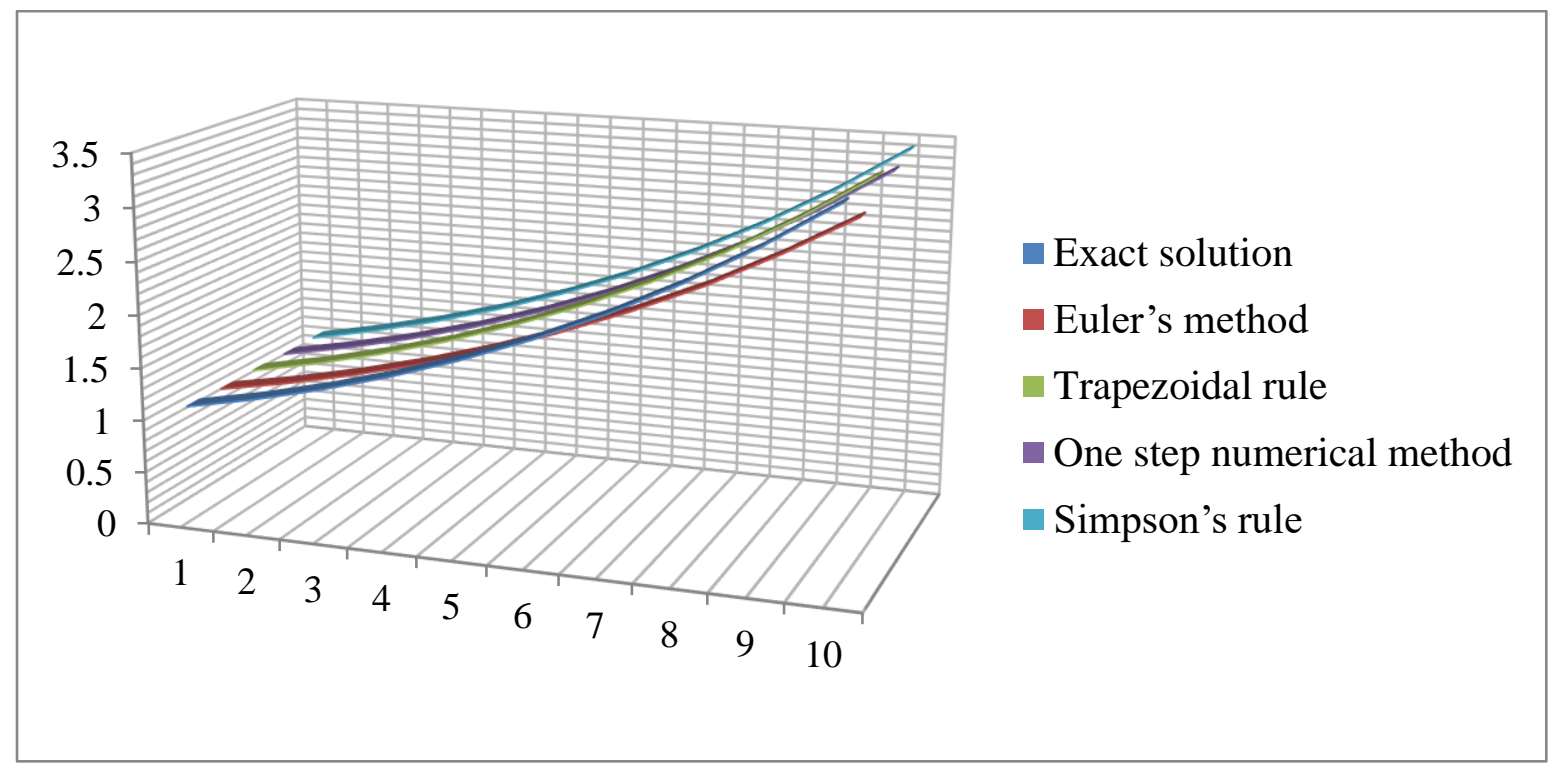

Figure 1: Graphical interpretation of Table 1

Table 2: Errors obtained for problem 1 at $h=0.1$

\begin{tabular}{|c|c|c|c|}
\hline $\begin{array}{c}\text { Euler's } \\
\text { Method }\end{array}$ & $\begin{array}{c}\text { Trapezoidal } \\
\text { Rule }\end{array}$ & $\begin{array}{c}\text { One Step } \\
\text { Numerical } \\
\text { Method }\end{array}$ & $\begin{array}{c}\text { Simpson's } \\
\text { Rule }\end{array}$ \\
\hline $1.034184 \mathrm{e}-002$ & $3.418362 \mathrm{e}-004$ & $5.175110 \mathrm{e}-003$ & $3.418362 \mathrm{e}-004$ \\
\hline $1.280552 \mathrm{e}-002$ & $7.555163 \mathrm{e}-004$ & $1.089537 \mathrm{e}-002$ & $1.388497 \mathrm{e}-004$ \\
\hline $3.771762 \mathrm{e}-002$ & $1.252365 \mathrm{e}-003$ & $1.721835 \mathrm{e}-002$ & $5.709485 \mathrm{e}-004$ \\
\hline $5.544940 \mathrm{e}-002$ & $1.845294 \mathrm{e}-003$ & $2.420723 \mathrm{e}-002$ & $1.092329 \mathrm{e}-003$ \\
\hline $7.642254 \mathrm{e}-002$ & $2.549010 \mathrm{e}-003$ & $3.193235 \mathrm{e}-002$ & $1.716983 \mathrm{e}-003$ \\
\hline $1.011156 \mathrm{e}-001$ & $3.380248 \mathrm{e}-003$ & $4.047132 \mathrm{e}-002$ & $2.460858 \mathrm{e}-003$ \\
\hline $1.300712 \mathrm{e}-001$ & $4.358040 \mathrm{e}-003$ & $4.990959 \mathrm{e}-002$ & $3.342115 \mathrm{e}-003$ \\
\hline $1.639042 \mathrm{e}-001$ & $5.504008 \mathrm{e}-003$ & $6.034231 \mathrm{e}-002$ & $4.381410 \mathrm{e}-003$ \\
\hline $2.033108 \mathrm{e}-001$ & $6.842699 \mathrm{e}-003$ & $7.187414 \mathrm{e}-002$ & $5.602229 \mathrm{e}-003$ \\
\hline $2.490787 \mathrm{e}-001$ & $8.401964 \mathrm{e}-003$ & $8.462048 \mathrm{e}-002$ & $7.031244 \mathrm{e}-003$ \\
& & & \\
\hline & & & \\
\hline
\end{tabular}




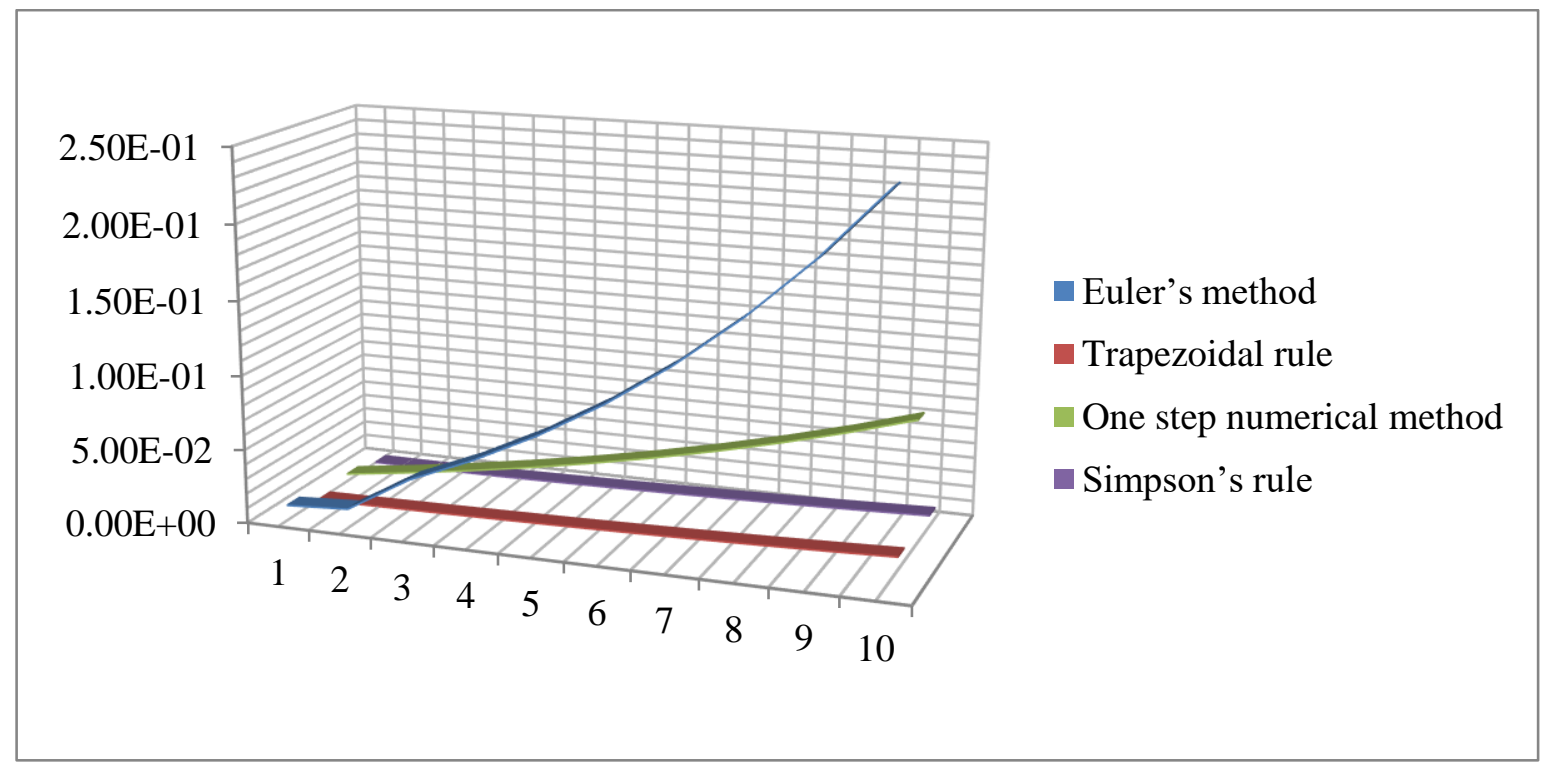

Figure 2: Graphical interpretation of Table 2

\section{Example 2}

$y^{\prime}=-y, y(0)=1$ with $h=0.1$

The exact solution is obtained as $y(x)=e^{-x}$
The results and the errors incurred are shown in Tables 3 and 4 respectively.

Table 3: Results for problem 2 at $h=0.1$

\begin{tabular}{|c|c|c|c|c|}
\hline $\begin{array}{c}\text { Exact } \\
\text { Solution }\end{array}$ & $\begin{array}{c}\text { Euler's } \\
\text { Method }\end{array}$ & $\begin{array}{c}\text { Trapezoidal } \\
\text { Rule }\end{array}$ & $\begin{array}{c}\text { One Step } \\
\text { Numerical } \\
\text { Method }\end{array}$ & $\begin{array}{c}\text { Simpson's } \\
\text { Rule }\end{array}$ \\
\hline 0.90483743 & 0.90000000 & 0.90500000 & 0.89483333 & 0.90500000 \\
\hline 0.81873077 & 0.81000001 & 0.81902500 & 0.80072665 & 0.81866666 \\
\hline 0.74081820 & 0.72900001 & 0.74121762 & 0.71651691 & 0.74089333 \\
\hline 0.67032003 & 0.65610000 & 0.67080195 & 0.64116323 & 0.67050846 \\
\hline 0.60653067 & 0.59049000 & 0.60707576 & 0.57373422 & 0.60681016 \\
\hline 0.54881161 & 0.53144100 & 0.54940356 & 0.51339650 & 0.54916319 \\
\hline 0.49658531 & 0.47829690 & 0.49721022 & 0.45940429 & 0.49699269 \\
\hline 0.44932896 & 0.43046721 & 0.44997525 & 0.41109028 & 0.44932896 \\
\hline 0.40656966 & 0.38742048 & 0.40722760 & 0.36785728 & 0.40704944 \\
\hline 0.36787945 & 0.34678440 & 0.36854098 & 0.32917094 & 0.36837974 \\
\hline
\end{tabular}




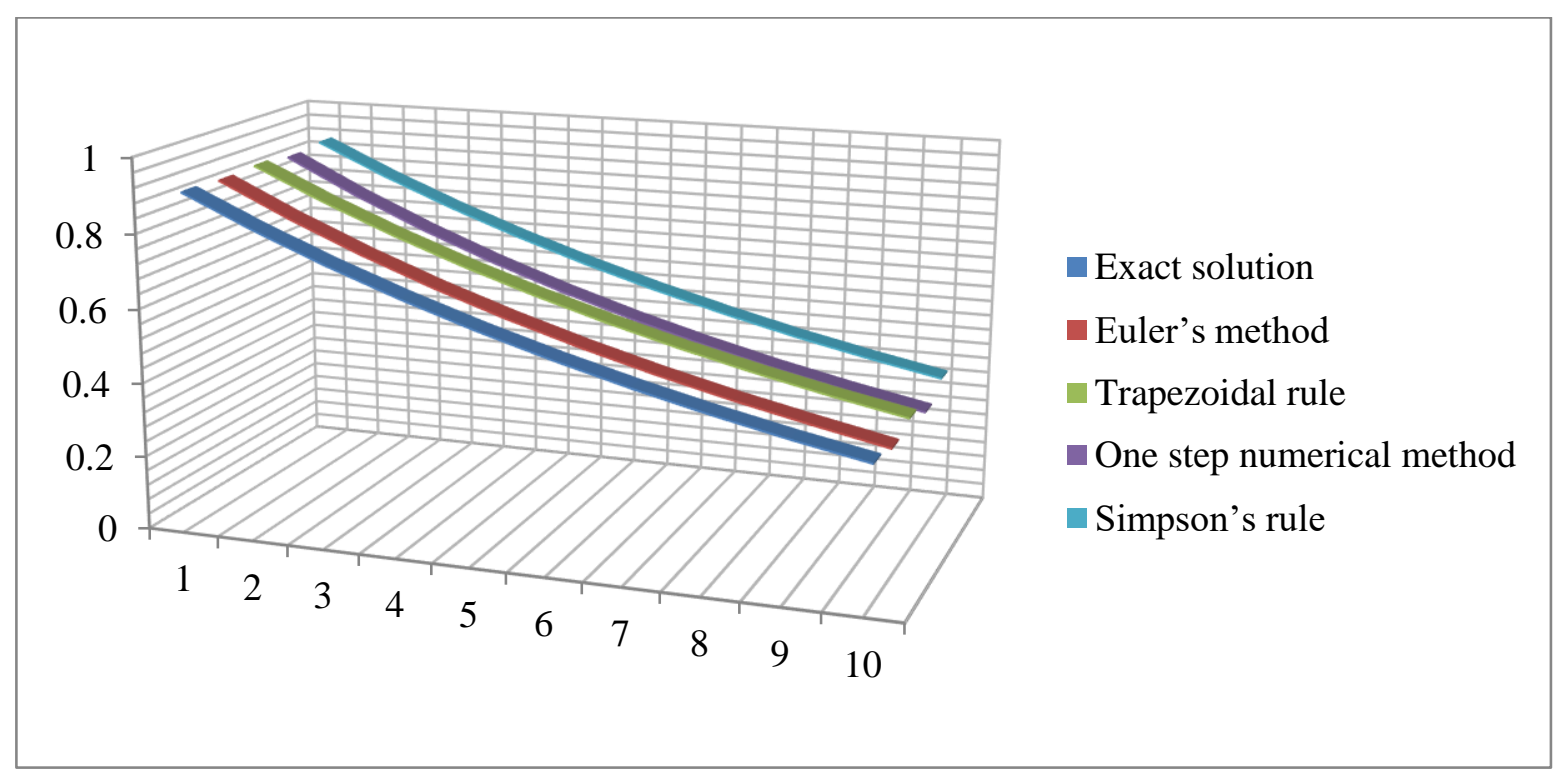

Figure 3: Graphical interpretation of Table 3

Table 4: Errors obtained for problem 2 at $h=0.1$

\begin{tabular}{|c|c|c|c|}
\hline $\begin{array}{c}\text { Euler's } \\
\text { Method }\end{array}$ & $\begin{array}{c}\text { Trapezoidal } \\
\text { Rule }\end{array}$ & $\begin{array}{c}\text { One Step } \\
\text { Numerical } \\
\text { Method }\end{array}$ & $\begin{array}{c}\text { Simpson's } \\
\text { Rule }\end{array}$ \\
\hline $4.837418 \mathrm{e}-003$ & $1.625820 \mathrm{e}-004$ & $1.000410 \mathrm{e}-002$ & $1.625820 \mathrm{e}-004$ \\
\hline $8.730753 \mathrm{e}-003$ & $2.942469 \mathrm{e}-004$ & $1.800412 \mathrm{e}-002$ & $6.408641 \mathrm{e}-005$ \\
\hline $1.181822 \mathrm{e}-002$ & $3.994043 \mathrm{e}-004$ & $2430129 \mathrm{e}-002$ & $7.511265 \mathrm{e}-005$ \\
\hline $1.422005 \mathrm{e}-002$ & $4.819046 \mathrm{e}-004$ & $2.915680 \mathrm{e}-002$ & $1.884206 \mathrm{e}-004$ \\
\hline $1.604066 \mathrm{e}-002$ & $5.451056 \mathrm{e}-004$ & $3.279644 \mathrm{e}-002$ & $2.795026 \mathrm{e}-004$ \\
\hline $1.737064 \mathrm{e}-002$ & $5.919315 \mathrm{e}-004$ & $3.541511 \mathrm{e}-002$ & $3.515608 \mathrm{e}-004$ \\
\hline $1.828840 \mathrm{e}-004$ & $6.249249 \mathrm{e}-004$ & $3.718102 \mathrm{e}-002$ & $4.073894 \mathrm{e}-004$ \\
\hline $1.886175 \mathrm{e}-002$ & $6.462928 \mathrm{e}-004$ & $3.823867 \mathrm{e}-002$ & $4.494232 \mathrm{e}-004$ \\
\hline $1.914917 \mathrm{e}-002$ & $6.579478 \mathrm{e}-004$ & $3871238 \mathrm{e}-002$ & $4.797808 \mathrm{e}-004$ \\
\hline $1.920100 \mathrm{e}-002$ & $6.615437 \mathrm{e}-004$ & $3.870851 \mathrm{e}-002$ & $5.00325 \mathrm{e}-004$ \\
\hline & & & \\
\hline
\end{tabular}




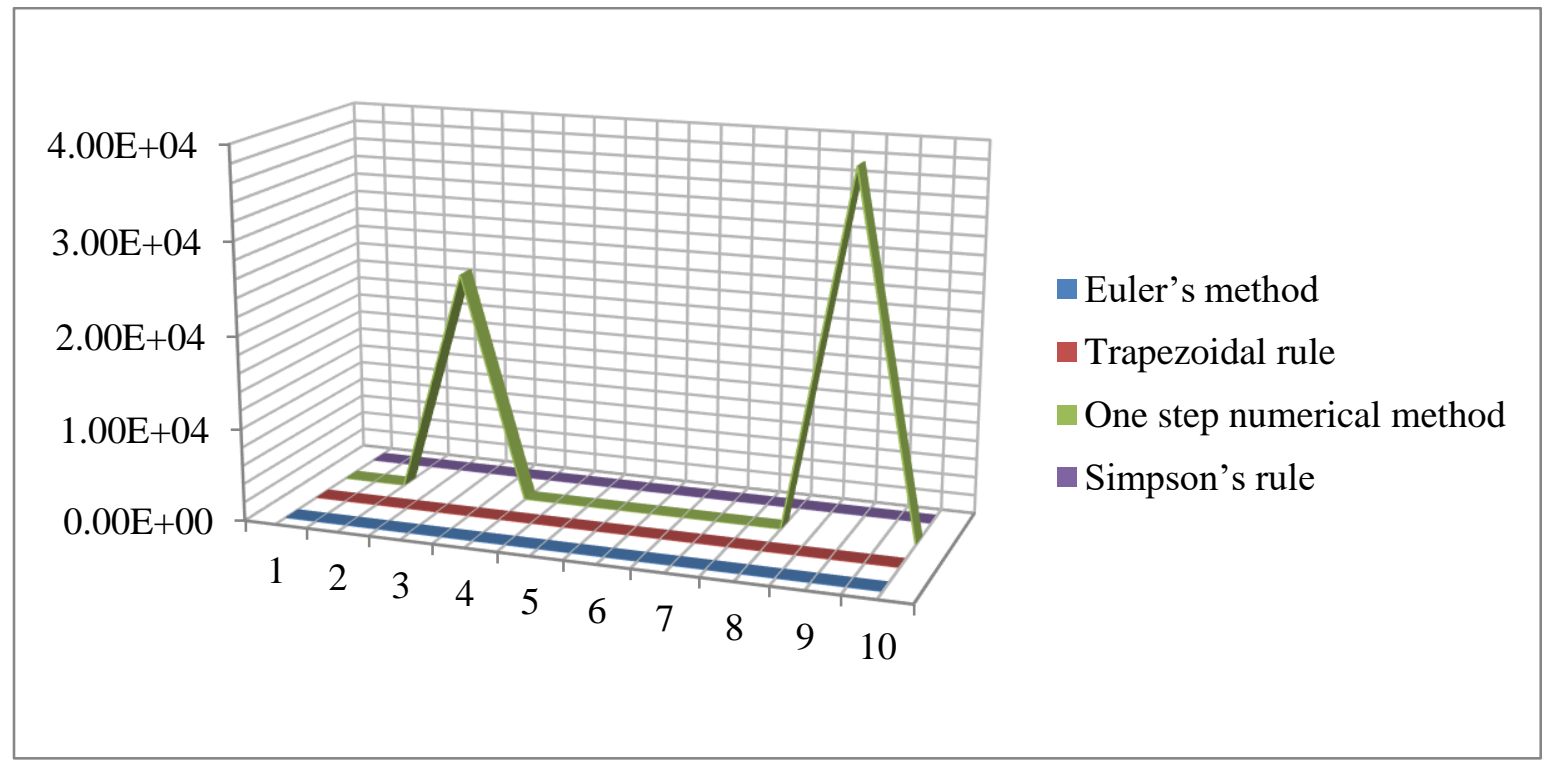

Figure 4: Graphical interpretation of Table 4

\subsection{DISCUSSION OF RESULTS AND CONCLUDING REMARKS}

In this paper, Euler's method, Trapezoidal rule, Simpson's rule and one-step numerical method was used to solve two sampled problems of first order ordinary differential equations in order to compare the results and determine if one-step numerical method is employable to solve such problems. Since the results and errors obtained via the newly developed method shown in Tables 1, 2 and Tables 3, 4 respectively, compared favorably with other existing methods, this shows that the new one step method performs better and is an alternative approach for solving initial value problems in ordinary differential equations. We recommend a further extension to this research in the area of applications. The scheme can still be implemented on other initial and boundary value problems of ordinary differential equations. Moreover, some of the problems arising from biological sciences, engineering and economics can be translated mathematically into an ordinary differential equation and we believe that the scheme could be of help to provide approximate solutions.

\section{Biography}

Fadugba Sunday Emmanuel is a Lecturer in the Department of Mathematics, Ekiti State University, Ado Ekiti, Nigeria. He is a registered Member of International Association of Engineers (IAENG). $\mathrm{He}$ is also a registered Professional Member of International Technology and Science Publications (ITS). He holds a Ph.D. Degree in Mathematics in the area of Financial Mathematics from the University of Ibadan, Nigeria. His research interests are in Numerical Analysis, Financial Mathematics and Stochastic Analysis with Applications.

Olaosebikan Tayo is a Ph.D. research student in the Department of Mathematics, Ekiti State University, Ado Ekiti, Nigeria. He holds a Master of Science in Mathematics from Ekiti State University, Ado Ekiti, Nigeria. His research interest is in Optimization and Numerical Analysis.

\section{References}

1 Aboiyar T., Luga T. and Ivorter B. V. (2015), Derivation of continuous linear multistep methods using Hermite polynomials as basis functions, American Journal of Applied Mathematics and Statistics, 3 (6), 220-225.

2 Butcher, J.C., Numerical Methods for Ordinary Differential Equation, West Sussex: John Wiley \& Sons Ltd, 2003. 
3 Fadugba, S.E. and Falodun, B. O., (2017), Development of a new one-step scheme for the solution of initial value problem (IVP) in ordinary differential equations, International Journal of Theoretical and Applied Mathematics, 3:58-63.

4 Fatunla, S.O., (1976), A new algorithm for the numerical solution of ODEs, Computers and Mathematics with Applications, 2: 247-253.

5 Ibijola, E.A. (1997), A new numerical scheme for the solution of initial value problems (IVPs), Ph.D. Thesis, University of Benin, Nigeria.

6 Ibijola, E.A., (1998), On the convergence, consistency and stability of a one-step method for Integration of ODEs, International Journal of Computer Mathematics, 73:261-277.

7 Kama, P. and Ibijola, E.A., (2000). On a new one - step Method for numerical integration of ordinary differential equations, International Journal of Computer Mathematics, 78, 21-29.

8 Lambert, J.D., Numerical methods for ordinary differential systems: the initial value problem. John Wiley \& Sons, Inc., New York, 1991.

9 Zarina, B.I., Mohammed, S., Kharil, I. and Zanariah, M., Block method for generalized multistep Adams method and backward differentiation formula in solving first-order ODEs, Mathematika, 2005. 